\title{
Working
}

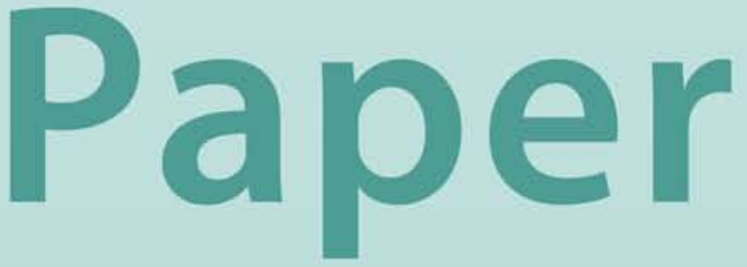


IMF Working Paper

(C) 1999 International Monetary Fund
This is a Working Paper and the author(s) would welcome any comments on the present text. Citations should refer to a Working Paper of the International Monetary Fund. The views expressed are those of the author(s) and do not necessarily represent those of the Fund.
WP $/ 99 / 60$
INTERNATIONAL MONETARY FUND

Fiscal Affairs Department

\section{Inequality and Optimal Redistributive Tax and Transfer Policies}

Prepared by Howell H. Zee

April 1999

\begin{abstract}
This paper explores the revenue-raising aspect of progressive taxation and derives, on the basis of a simple model, the optimal degree of tax progressivity where the tax revenue is used exclusively to finance (perfectly) targeted transfers to the poor. The paper shows that not only would it be optimal to finance the targeted transfers with progressive taxation, but that the optimal progressivity increases unambiguously with growing income inequality. This conclusion holds up under different assumptions about the efficiency cost of taxation and society's aversion to inequality.
\end{abstract}

JEL Classification Numbers: H21, H53

Keywords: inequality, progressive taxation, optimal taxation, transfer policy Author's E-Mail Address: hzee@imforg

${ }^{1}$ In writing this paper, I have benefited from conversations with and/or comments on an earlier draft of the paper from many people, especially Eric Haindl, John King, Martin McGuire, and Vito Tanzi. The usual disclaimer applies, of course. 


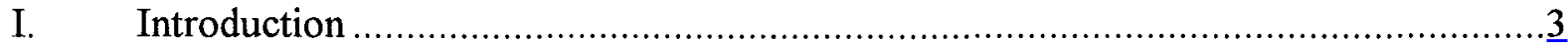

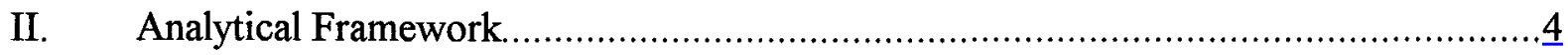

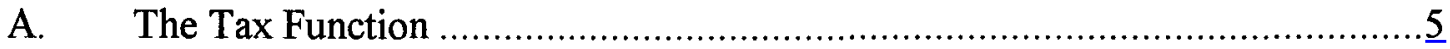

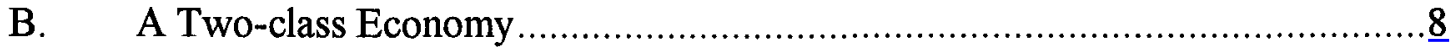

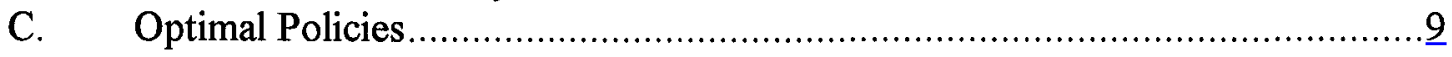

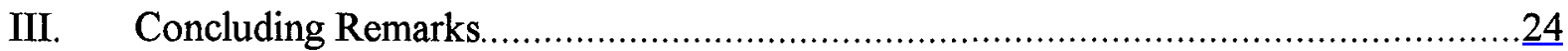

\section{Tables}

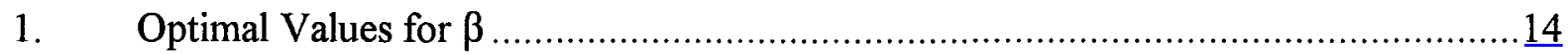

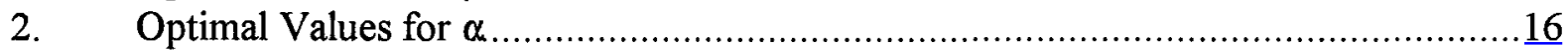

3. Average Tax Rates (low efficiency cost and high inequality aversion)....................18

4. Marginal Tax Rates (low efficiency cost and high inequality aversion)....................19

5. Modified Average Rate Progression.............................................................. 21

6. Average Tax Rates (high efficiency cost and high inequality aversion) ....................22

7. Marginal Tax Rates (high efficiency cost and high inequality aversion)....................23

8. Average Tax Rates (high efficiency cost and low inequality aversion) ..................... 25

9. Marginal Tax Rates (high efficiency cost and low inequality aversion)....................26

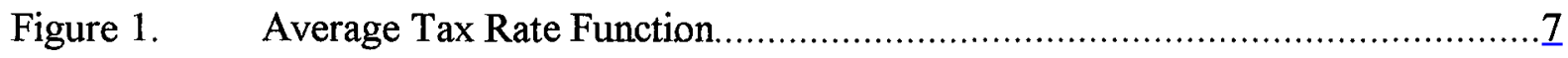

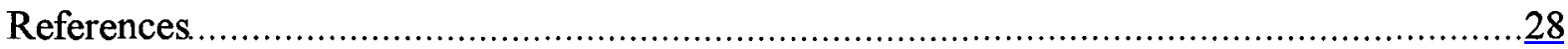




\section{INTRODUCTION}

Redistributing income through progressive taxation is an idea that has fallen very much into disfavor in the past two decades. A number of factors, theoretical and empirical, contributed to this development. On the theoretical front, the focus has been on the disincentive effects of high tax progressivity. In his seminal contribution, Mirrlees (1971) showed that, based on certain plausible parameter values about the underlying earnings distribution, labor supply elasticity, and society's inequality aversion, the optimal tax function is approximately linear-with moderate average and marginal tax rates (in most cases below 40 percent). Much of the subsequent literature on optimal income taxation has been concerned with performing sensitivity analyses of the response of the optimal tax rate to variations in model parameters, based on a linear tax function. ${ }^{2}$

On the empirical front, it has been argued that, based on country experiences, the effectiveness of progressive taxation in altering the posttax distribution of income has been limited, suggesting that the tax system is not among the most important determinants of the income distribution in a country. ${ }^{3}$ Evidently, many countries have found the case against high tax progressivity compelling, and the flattening out of the tax rate schedule (lowering the top rates and increasing the bottom rates) has been one of the most notable features of tax reforms implemented around the world in recent years. ${ }^{4}$

If income redistribution cannot be pursued effectively on the tax side, then it would be natural to argue that equity objectives be addressed on the expenditure side, especially through targeted transfers to the poor in the short run and public spending for human capital accumulation in the long run. ${ }^{5}$ Implicit in this argument is, of course, that the required expenditure be financed by broadly neutral taxes. While intuitively appealing, this line of reasoning overlooks a crucial conceptual consideration as regards progressive taxation: it is better able to raise the revenue to finance the expenditure-in a way that supports the

${ }^{2}$ See, for example, Atkinson (1983), Cooter and Helpman (1974), Helpman and Sadka (1978), and Stern (1976). An exception is Tuomala (1990), who performed simulations on a nonlinear tax function. The general results of this literature are well known, and are reviewed in Tuomala (1990).

${ }^{3}$ See Harberger (1998) and Tanzi (1974). Tanzi (1998) noted a number of practical reasons for this, including administrative and evasion problems associated with high tax progressivity, as well as the difficulty in taxing wealth - often a major determinant of income distribution.

${ }^{4}$ See Messere (1993) for a comprehensive review of reform experiences in OECD countries. Lessening the degree of tax progressivity has also been the IMF's policy advice to many developing countries (Tanzi (1994)).

${ }^{5}$ See Harberger (1998), Tanzi (1998), and Tanzi and Chu (1998). 
underlying redistributive objective-than neutral taxation, and that this ability becomes more important the more unequal is the distribution of income. In other words, once expenditure is brought into the picture, the question of its effective financing becomes front and center, and it is here that the efficacy of progressive taxation unexpectedly gains a new dimension. In designing equity-oriented expenditure programs, the role of progressive taxation-not as a device for lessening inequality directly but as a means for raising revenue to finance such programs-cannot be so easily dismissed on conceptual grounds. ${ }^{6}$

This paper explores the revenue-raising aspect of progressive taxation and derives, on the basis of a simple model, the optimal degree of tax progressivity where the tax revenue is used exclusively to finance (perfectly) targeted transfers to the poor. This aspect of progressive taxation has largely been ignored by the literature on optimal income taxation, as it seldom addresses the redistributive implications of government expenditures. ${ }^{7}$ The results of the paper show that not only would it be optimal to finance the targeted transfers with progressive taxation, but that the optimal progressivity increases unambiguously with growing income inequality. This conclusion holds up under different assumptions about the efficiency cost of taxation and society's aversion to inequality.

An interesting aspect of the paper's investigation is that it reveals that the advantage of progressive taxation for revenue-raising purposes is at its strongest at relatively low levels of aggregate income, and that this advantage fades as aggregate income rises. While this result makes intuitive sense--the rich in a poor country should be taxed more heavily than the rich in a rich country (relative to the poor in their respective countries) because the poor in the rich country is richer than the poor in the poor country - it does give rise to an intriguing implication that it would be optimal for developing countries to have a more progressive tax structure than developed countries. Of course, as a practical policy matter this implication would have to be substantially tempered by other considerations against progressive taxation, such as those discussed in Tanzi (1998), which have been ignored in this paper.

\section{ANALYTICAL FRAMEWORK}

To render the analysis in its simplest terms, consider a model in which the sole policy objective of the government is to redistribute income from the rich to the poor through

\footnotetext{
${ }^{6}$ In a different context, Tanzi (1966) also recognized the revenue-raising potential of progressive income taxation.
}

${ }^{7}$ The typical setup of an optimal income tax problem is that the government is required to raise a fixed amount of revenue (which could be zero)-but not for redistributive purposes, i.e., targeted transfers to the poor. If the revenue requirement is set at zero, the revenue raised by the tax would have to be returned as lump-sum transfers to all taxpayers (see, for example, Phelps (1973)). In models with a linear tax function, (uniform) lump-sum transfers are obviously necessary to render a linear tax progressive (in the average sense). 
targeted transfers financed by either a proportional or a progressive income tax. The optimal size of the transfer and the optimal form of the income tax are, therefore, simultaneous solutions to the government's problem of maximizing a social welfare function that displays some given degree of aversion to income inequality.

\section{A. The Tax Function}

A crucial building block of the analysis is the choice of a specific functional form for the tax function that is at once simple enough to allow for the derivation of closed-form solutions and flexible enough to encompass both proportional and progressive forms of taxing income. One nonlinear average tax rate function, $a$, that serves this purpose is

$$
a=\alpha-y^{-\beta}, \quad \alpha \geq 0, \quad 1 \geq \beta \geq 0,
$$

where $y$ is pretax income. To ensure that $a \geq 0$, it is necessary to exclude the range of pretax income $y<(1 / \alpha)^{1 / \beta}$ from consideration. The closer is $\alpha$ to unity from below, the less restrictive will be this exclusion. Notwithstanding such a restriction, it will proof analytically convenient for later discussions to always exclude a small range of $y$. Specifically, attention henceforth will be restricted to pretax income at least above a minimal level of

$$
y \geq e \Leftrightarrow \ln y \geq 1
$$

There is no a priori restriction on $\alpha$ not to exceed unity. Nevertheless, to rule out the possibility that the average tax rate would exceed 100 percent, it is necessary to impose the condition $\alpha \leq 1+y^{-\beta}$. A version of equation (1), with $\alpha$ set at unity, was first proposed by Edgeworth (1925) in his discussion of different progressive tax formulae, and was later derived by Dalton (1967) on the basis of a Bernouilli utility function combined with the principle of proportional sacrifice.

Given equation (1), the tax revenue function, $r$, can then be stated as

$$
r \equiv a \cdot y=\alpha \cdot y-y^{1-\beta}
$$

from which the marginal tax rate function, $m$, can be expressed as

$$
m \equiv \partial r / \partial y=\alpha-(1-\beta) \cdot y^{-\beta}
$$

Note that the tax revenue function is progressive in the conventional sense, i.e., $m>a$, whenever $\beta>0$. Specifically, $r$ would satisfy all four of the well-known concepts of progressivity as advanced by Musgrave and Thin (1948) (see also the discussion by Lambert (1993)) if $\beta$ is positive but less than unity. For the case of $\beta=0$, it follows immediately from equation (3) that the tax revenue function is proportional at the rate $\alpha-1$, which is, of course, also the average and marginal tax rates. Note also that, for any given value of $1>\beta>0$, the 
tax revenue function also tends towards proportionality, albeit asymptotically, as $y \rightarrow \infty$, with both the average and marginal rates tending asymptotically towards the rate $\alpha$.

One way of interpreting the relative roles played by the parameters $\alpha$ and $\beta$ in equation (1) is to note that $m$ rises with income-labeled as marginal rate progression $(M R P)$ by Musgrave and Thin (1948) and is associated with the most common notion of progressivity-and this rise is independent of $\alpha$ :

$$
M R P \equiv \partial m / \partial y=\beta \cdot(1-\beta) \cdot y^{-(1+\beta)}>0 \text { if } 1>\beta>0
$$

Hence, it would be intuitive to regard $\alpha$ as the proportionality parameter and $\beta$ the progressivity parameter. It is interesting to observe, however, that the relationship between the $M R P$ and $\beta$ is not monotonic, since

$$
\partial M R P / \partial \beta=[1-2 \beta-(1-\beta) \cdot \beta \cdot \ln y] \cdot y^{-(1+\beta)} \geq 0 \text { as }(1-2 \beta) /[(1-\beta) \cdot \beta] \geq \ln y \text {. }
$$

Given that $\ln y$ is always positive as imposed by equation (2), a higher $\beta$ will necessarily lower the $M R P$ whenever $\beta>0.5$.

Another concept of progressivity advanced by Musgrave and Thin (1948)-the so-called average rate progression $(A R P)$-is also of interest:

$$
A R P \equiv \partial a / \partial y=(m-a) / y=\beta \cdot y^{-(1+\beta)}>0 \text { if } \beta>0 .
$$

Hence, $a$ also rises with income and this rise is again independent of $\alpha$. Equation (7) makes it clear that any change in the $A P R$ measures a change in the marginal tax rate relative to that in the average tax rate. Since a rise in $\beta$ raises both the marginal and average tax rates, the relationship between $A R P$ and $\beta$ is--similar to that between $M R P$ and $\beta$-not monotonic. ${ }^{8}$ Directly from equation (7),

$$
\partial A R P / \partial \beta=(1-\beta \cdot \ln y) \cdot y^{-(1+\beta)} \geq 0 \text { as } 1 / \beta \geq \ln y .
$$

It is evident from equation (8) that, for a given value of pretax income, as $\beta$ is increased from zero, the $A P R$ first rises, reaches a maximum at $\beta=1 / \ln y$, and then declines afterwards.

An illustration of the average tax rate function (equation (1)) is provided in the two panels of Figure 1. In the upper panel, the two components of equation (1) are shown separately. The first component is simply a horizontal line, while the second component is a downward sloping curve that approaches both axes asymptotically. The average tax rate in this panel can, therefore, be measured as the vertical distance between the two components at any given value of pretax income. The lower panel displays the average tax rate by itself, which is shown

\footnotetext{
${ }^{8} \mathrm{In}$ fact, an inspection of equation (5) and equation (7) reveals that $M R P=(1-\beta) \cdot A R P$.
} 
Figure 1. Average Tax Rate Function
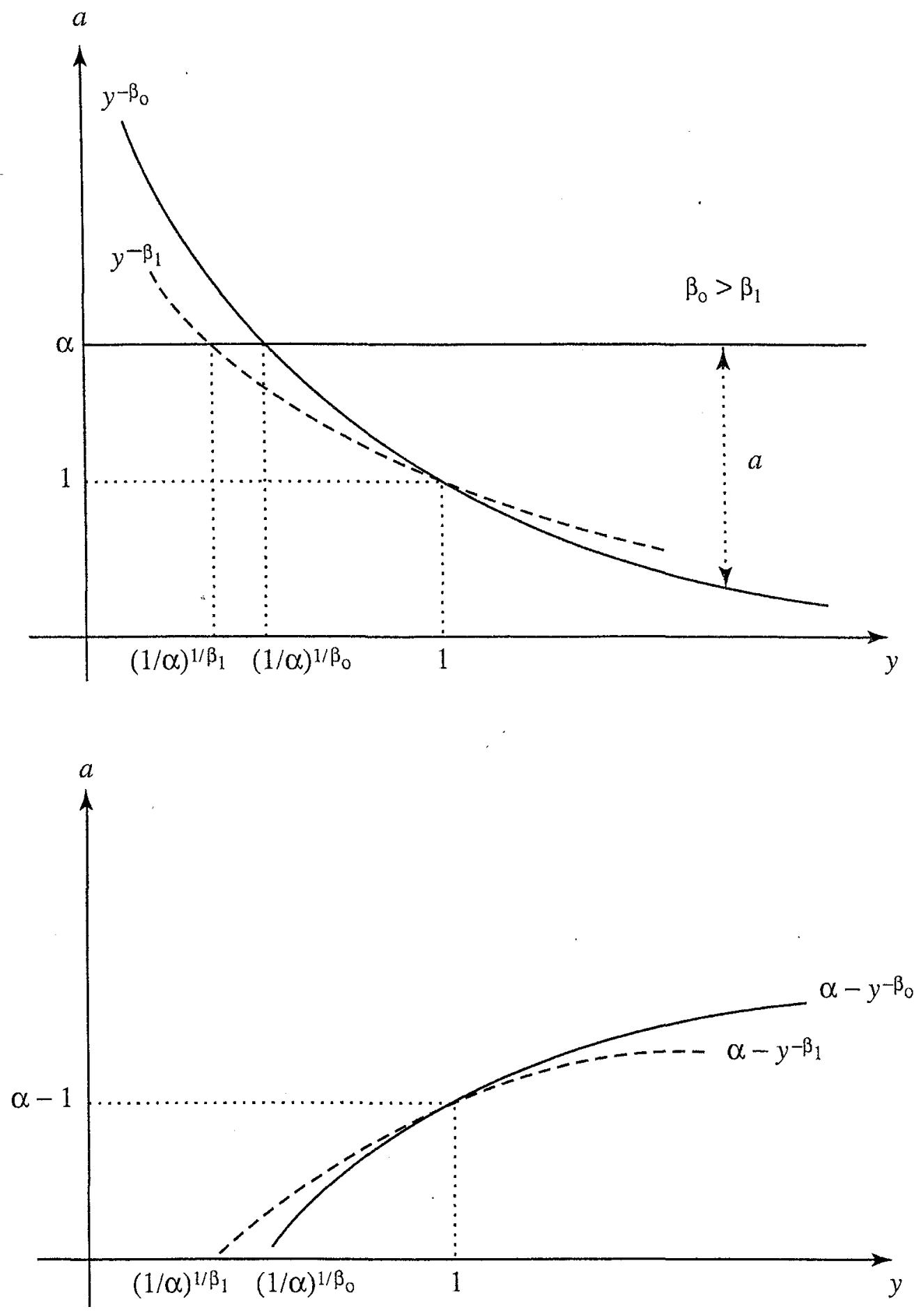
to be an increasing function of pretax income (albeit at a decreasing rate). All things equal, a decrease in $\beta$, say, from $\beta_{0}$ to $\beta_{1}$, would rotate the second component of the average tax rate function around the coordinates $(y=1, a=1)$ in a counter-clockwise fashion (upper panel of figure 1), but would rotate the entire average tax function around the coordinates $(y=1, a=$ $\alpha-1$ ) in a clockwise fashion (lower panel of Figure 1). In the limit as $\beta$ is reduced to zero, the average tax rate function would become a horizontal line, giving a constant rate of $\alpha-1$.

\section{B. A Two-class Economy}

Consider an economy with two individuals, $A$ and $B$, and $A$ is at least as well off as $B$. The pretax income of the two individuals are

$$
\begin{aligned}
& y_{A}=\phi \cdot 2 z, \quad 1 \geq \phi \geq 0.5 \text { and } \\
& y_{B}=(1-\phi) \cdot 2 z,
\end{aligned}
$$

where $2 z$ (with $z \geq e$ ) is the economy's aggregate pretax income, with perfect equality given by $\phi=0.5$. Equation (9) implies that a change in $\phi$ changes the degree of relative inequality (i.e., the ratio of the pretax income of individual $A$ to that of individual $B$ ), while a change in $z$, with $\phi$ held constant (except at $\phi=0.5$ ), changes the degree of absolute inequality (i.e., the difference between the two individuals' pretax income levels). ${ }^{9}$ On the basis of the tax revenue function given by equation (3), tax payments of $A$ and $B$ are, respectively,

$$
\begin{aligned}
& r_{A}=\alpha \cdot \phi \cdot 2 z-\phi^{1-\beta} \cdot(2 z)^{1-\beta} \text { and } \\
& r_{B}=\alpha \cdot(1-\phi) \cdot 2 z-(1-\phi)^{1-\beta} \cdot(2 z)^{1-\beta}
\end{aligned}
$$

and the aggregate tax payment is

$$
g \equiv r_{A}+r_{B}=\alpha \cdot 2 z-\left[\phi^{1-\beta}+(1-\phi)^{1-\beta}\right] \cdot(2 z)^{1-\beta} \text {. }
$$

The simplest and most straightforward way to capture the idea of (perfectly) targeted transfers is to assume that $B$ receives the entire tax payment, net of some efficiency cost of taxation, $c(g)$, which rises with the amount of tax revenue raised, i.e., $\partial c / \partial g>0$. Let $q_{A}$ and $q_{B}$ be the posttax income ${ }^{10}$ of $A$ and $B$, respectively. It then follows that, by using equations (9) and (10)-(12),

\footnotetext{
${ }^{9}$ Note that a change in relative inequality also changes absolute inequality, but not necessarily vice versa.

${ }^{10}$ Henceforth, the term posttax income refers to income after tax cum transfers.
} 


$$
\begin{aligned}
& q_{A} \equiv y_{A}-r_{A}=(1-\alpha) \cdot \phi \cdot 2 z+\phi^{1-\beta} \cdot(2 z)^{1-\beta} \text { and } \\
& q_{B} \equiv y_{B}-r_{B}+g-c=[1-\phi \cdot(1-\alpha)] \cdot 2 z-\phi^{1-\beta} \cdot(2 z)^{1-\beta}-c
\end{aligned}
$$

It would be useful to note for later reference that the impacts of changes in the tax parameters on the individuals' posttax income are

$$
\begin{aligned}
& \partial q_{A} / \partial \alpha=-\phi \cdot 2 z \\
& \partial q_{A} / \partial \beta=-\phi^{1-\beta} \cdot(2 z)^{1-\beta} \cdot \ln (\phi \cdot 2 z) \\
& \partial q_{B} / \partial \alpha=\phi \cdot 2 z-\partial c / \partial \alpha, \text { and } \\
& \partial q_{B} / \partial \beta=\phi^{1-\beta} \cdot(2 z)^{1-\beta} \cdot \ln (\phi \cdot 2 z)-\partial c / \partial \beta
\end{aligned}
$$

Equations (15)-(18) make it clear that a rise in either $\alpha$ or $\beta$, which in either case represents a rise in taxation, would reduce $A$ 's posttax income. Furthermore, the amount of $A$ 's loss would have been exactly equal to the amount of $B$ 's gain, were it not for the fact that raising the revenue through taxation to effect the transfers entails a cost.

\section{Optimal Policies}

The problem of optimal tax and transfer policies posed in this paper is interesting and meaningful, of course, only if society displays some aversion to inequality in income distribution. It is analytically convenient to represent this aversion by the following social welfare function $w$ that is concave in the posttax income of $A$ and $B$ :

$$
\begin{aligned}
& w=-\exp \left(-\epsilon \cdot q_{A}\right) / \epsilon-\exp \left(-\epsilon \cdot q_{B}\right) / \epsilon, \quad \epsilon>0, \\
& w=q_{A}+q_{B}, \quad \epsilon=0 .
\end{aligned}
$$

Equation (19) is a variation of the familiar Atkinson welfare function (see Atkinson (1983)) with $\epsilon$ as a parameter that could be varied to represent different degrees of inequality aversion. Specifically, the higher the value of $\epsilon$, the greater is this aversion, with $\epsilon=0$ being the Utilitarian case of no aversion and $\epsilon \rightarrow \infty$ being the Rawlsian case of maximum aversion. The optimization calculus of the government is, therefore, to maximize $w$ with respect to $\alpha$ and $\beta$, i.e., to determine the optimal shape of the tax function as given by equation (1) that would maximize social welfare. The two first-order conditions for maximum welfare are

$$
\begin{aligned}
& \left(\partial q_{A} / \partial \alpha\right) /\left(\partial q_{A} / \partial \beta\right)=\left(\partial q_{B} / \partial \alpha\right) /\left(\partial q_{B} / \partial \beta\right) \text { and } \\
& \exp \left[-\epsilon \cdot\left(q_{A}-q_{B}\right)\right]=-\left(\partial q_{B} / \partial \alpha\right) /\left(\partial q_{A} / \partial \alpha\right)
\end{aligned}
$$


At the optimum, equation (20) states that the ratio of the effect of a marginal change in $\alpha$ to that of $\beta$ on $A$ 's posttax income must be equalized with the same ratio as it pertains to $B$ 's posttax income, while equation (21) states that the (negative) of the ratio of the effect of a marginal change in $\alpha$ on $B^{\prime}$ 's posttax income to that on $A^{\prime}$ 's posttax income must be equalized with the excess of $A$ 's over $B$ 's posttax income weighted by the degree of inequality aversion. ${ }^{11}$ By using equations (15)-(18), equations (20) and (21) can be restated as, respectively,

$$
\begin{aligned}
& (\partial c / \partial \beta) /(\partial c / \partial \alpha)=\phi^{-\beta} \cdot(2 z)^{-\beta} \cdot \ln (\phi \cdot 2 z) \text { and } \\
& \exp \left[-\epsilon \cdot\left(q_{A}-q_{B}\right)\right]=1-(\partial c / \partial \alpha) /(\phi \cdot 2 z)
\end{aligned}
$$

It is evident from equations (22) and (23) that the efficiency cost of taxation plays a central role in determining the character of the optimal solution. For example, if either $\partial c / \partial \alpha$ or $\partial c / \partial \beta$ is zero, equation (22) would degenerate and equation (23) indicates that it would always be optimal to achieve perfect equality in posttax income, i.e., $q_{A}=q_{B}$, irrespective of society's degree of inequality aversion. Hence, to make further headway in evaluating the policy implications of the optimal solution, a more concrete specification of the nature of this cost is necessary. A simple and tractable specification of the cost function would be

$$
c=\lambda \cdot g, \quad 1>\lambda>0,
$$

which states that the cost is proportional to the revenue raised. ${ }^{12}$ Substituting equation (13) for $g$ in equation (24), it is straightforward to obtain

$$
\begin{aligned}
& \partial c / \partial \alpha=\lambda \cdot 2 z \text { and } \\
& \partial c / \partial \beta=\lambda \cdot\left\{\phi^{1-\beta} \cdot \ln \phi+(1-\phi)^{1-\beta} \cdot \ln (1-\phi)+\left[\phi^{1-\beta}+(1-\phi)^{1-\beta}\right] \cdot \ln (2 z)\right\} \cdot(2 z)^{1-\beta}
\end{aligned}
$$

\section{Optimal solution for $\beta$}

Armed with equations (25) and (26), a closed-form solution for the optimal value for $\beta$, denoted by $\beta^{*}$, is derivable directly from the first-order condition (22):

\footnotetext{
${ }^{11}$ Equation (21) can be equivalently stated in terms of a marginal change in $\beta$ instead of $\alpha$. These two alternative ways of stating the equation are obviously not independent of each other.

${ }^{12}$ This formulation of the efficiency cost of taxation is admittedly somewhat ad hoc and is employed here purely for analytical simplicity; it does not do full justice to all aspects of the disincentive effects of taxation. For example, an explicit utility maximization model of laborleisure choice would generally result in a cost function that is increasing in the revenue raised.
} 


$$
\beta^{*}=\frac{\ln \{\ln (\phi \cdot 2 z) / \ln [(1-\phi) \cdot 2 z]\}}{\ln [\phi /(1-\phi)]} \geq 0
$$

A remarkable aspect of equation (27) is that $\beta^{*}$ is not only independent of the other parameter of the tax function, i.e., $\alpha$, it is also independent of the degree of inequality aversion $\epsilon$. Indeed, $\beta^{*}$ is determined solely by the pretax income of $A$ relative to that of $B$, both in absolute terms (the ratio inside the curly brackets in the numerator of equation (27)) and in relative terms (the ratio inside the square brackets in the denominator of equation (27)). An intuitive interpretation of this result is that $\beta^{*}$ is governed by considerations relating to raising a given amount of revenue in the most effective manner possible, and not by those relating to determining the optimal amount of revenue to be raised and transferred (since it is independent of $\epsilon$ ). The solution to the latter problem is to be found in the optimal value for $\alpha$, which $i s$ dependent on $\in$ (see below). For this reason, one could refer to $\beta$ as the revenueraising parameter, and $\alpha$ as the transfer parameter.

The most interesting aspect of equation (27) is that the response of $\beta^{*}$ to a change in $\phi$ (relative inequality), which may vary over the allowable range of $(0.5,1-e / 2 z)$, is very different from that to a change in $z$ (absolute inequality), which may vary over the allowable range of $(e, \infty) .^{13}$ An inspection of equation (27) indicates that, not surprisingly, $\beta^{*}$ is not well defined at $\phi=0.5$, because in the context of the present model, tax and transfer policies are superfluous under perfect equality of pretax income. Nevertheless, it can be shown that $\beta^{*}$ tends to a well-defined limit as the distribution of income approaches equality, since, by the L'Hôpital's rule,

$$
\lim _{\phi \rightarrow 1 / 2} \beta^{*} \equiv \beta_{\phi=L}^{*}=1 / \ln z, \quad 1 \geq \beta_{\phi=L}^{*} \geq 0 .
$$

Note that $\beta_{\phi=L}^{*}$ has an upper bound of unity at the lowest permissible level of pretax income $z$ $=e$, and a lower bound of zero as $z \rightarrow \infty$. This implies that, as long as there is equality in income distribution, the optimal tax function increasingly tends to a proportional one as the economy's aggregate income rises.

At the other extreme of income distribution, i.e., at the point of maximum permissible inequality of $\phi=1-e / 2 z, \beta^{*}$ takes on the value of

\footnotetext{
${ }^{13}$ The lower limit of $e$ for $z$ is stipulated by equation (2). It essentially serves to ensure that the logarithm of an individual's pretax income would not fall below unity. The upper limit of 1 $e / 2 z$ for $\phi$ serves the same purpose, i.e., to ensure $B$ 's pretax income $(1-\phi) \cdot 2 z$ would not fall below $e$. Clearly, when $z \rightarrow \infty$, $\phi$ 's upper limit goes to unity. Note, however, that when $z=e$, $\phi$ can take on only a single value of 0.5 . This is because when the economy's aggregate income is at its lowest permissible level of $2 e$, perfect equality is the only way to ensure that no individual's income would fall below $e$.
} 


$$
\beta_{\phi=\mathrm{U}}^{*}=\ln [\ln (2 z-e)] /[\ln (2 z-e)-1], \quad 1 \geq \beta_{\phi=\mathrm{U}}^{*} \geq 0 .
$$

Again, by the L'Hôpital's rule, it can easily be ascertained that, as $z \rightarrow \infty, \beta_{\phi=U}^{*} \rightarrow 0$ in the limit. ${ }^{14}$ Hence, the ranges over which $\beta^{*}$ would vary in response to changes in $z$ at both extremes of income distribution are bounded by the same limits of zero at the low end and unity at the high end. Furthermore, it can be shown directly from equation (27) that, for any given permissible value of $\phi$,

$$
\partial \beta^{*} / \partial z=\left\{[\ln (\phi \cdot 2 z)]^{-1}-[\ln ((1-\phi) \cdot 2 z)]^{-1}\right\} /\{2 z \cdot[\ln \phi-\ln (1-\phi)] \leq 0,
$$

as the numerator of equation (30) is necessarily nonpositive.

The above discussion has focused on the behavior of $\beta^{*}$ in response to changes in $z$, for given values of $\phi$. As has been pointed out earlier, as $z$ rises from $e$, the allowable range of $\phi$ also expands concomitantly. It is thus interesting to ascertain the way $\beta^{*}$ would respond to a change in $\phi$, for given values of $z>e$. Numerical calculations (see below) indicate that $\beta^{*}$ rises with inequality. The above results can be conveniently summarized in the following schematic presentation.
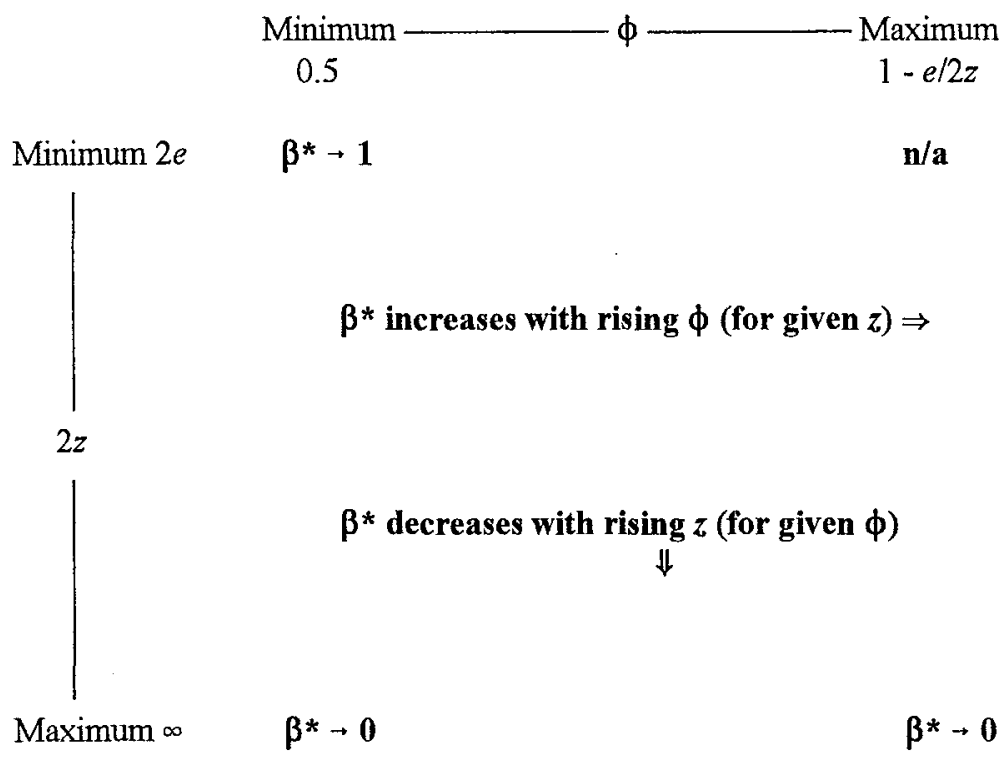

In reading the above schematic, it is important to visualize that the range for $\phi$ at the top expands to the right as one moves down the scale at the left for a higher $z$. This is the reason that there is no applicable value for $\beta^{*}$ at the upper right-hand corner of the schematic, since when $z=e$, the maximum and minimum values for $\phi$ collapse into a single value of 0.5 .

\footnotetext{
${ }^{14}$ As noted earlier, if $z=e, \phi$ is restricted to a single value of 0.5 , so that the outcome for $\beta_{\phi=\mathrm{U}}^{*}$ in this case would correspond to that given in equation (28), i.e., $\beta_{\phi=U}^{*}=1$. This result can also be directly obtained by applying the L'Hôpital's rule to equation (29) for the case of $z \rightarrow e$.
} 
Illustrative numerical calculations for $\beta^{*}$, based on alternative degrees of inequality and levels of aggregate pretax income, are provided in Table $1 .^{15}$

Table 1 indicates that the optimal value for $\beta$ decreases with increasing levels of aggregate pretax income (for a given degree of inequality), but increases with increasing degrees of relative inequality (for a given level of aggregate income). As discussed above, the optimal value for $\beta$ tends to zero at very high income levels, irrespective of the degree of inequality.

\section{Optimal solution for $\alpha$}

The optimal value for $\alpha$, denoted by $\alpha^{*}$, can be derived by first substituting equation (25) into equation (23) to yield

$$
q_{A}-q_{B}=\ln k / \epsilon
$$

where $k \equiv \phi /(\phi-\lambda)$ is a constant. For a meaningful solution for $\alpha$ to exist, it must be assumed that $\phi>\lambda$, or $k>1$, since otherwise raising $\alpha$ would not only yield no revenue to finance the transfers, it would actually result in a net loss of revenue to society as a whole. ${ }^{16}$ Equation (31) clearly indicates that the optimal degree of inequality in the distribution of posttax income between $A$ and $B$ is inversely related to the degree of society's aversion to inequality. As $\epsilon \rightarrow$ $\infty$, the optimal solution would be, as expected, the Rawlsian outcome of perfect equality, with $q_{A}=q_{B}$. Alternatively, had the pretax income been equally distributed initially, there would have been no need, of course, to carry out any tax and transfer policies in the first place. In this case, equation (31) could be interpreted as if $\epsilon \rightarrow \infty$. By utilizing equations (12)-(14) and (24), a closed-form solution for $\alpha^{*}$ could be obtained from equation (31) as

$$
\alpha^{*}=\frac{2 \phi-1}{2 \phi-\lambda}+\frac{\phi^{1-\beta^{*}} \cdot\left\{2-\lambda-\lambda \cdot[(1-\phi) / \phi]^{1-\beta^{*}}\right\}}{(2 \phi-\lambda) \cdot(2 z)^{\beta^{*}}}-\frac{\ln k / \epsilon}{(2 \phi-\lambda) \cdot(2 z)}
$$

which clearly indicates, as expected, that $\alpha^{*}$ increases with $\epsilon$, i.e., $\partial \alpha^{*} / \partial \epsilon>0$. Note, however, that $\epsilon$ appears only in the third term on the right-hand side of equation (32), which has $2 z$ as part of its denominator. Thus, the impact of variations in $\epsilon$ on $\alpha^{*}$ will diminish with rising levels of aggregate income. Equation (32) also indicates that the response of $\alpha^{*}$ to changes in either $\phi$ or $z$ is possibly complex and ambiguous. Notwithstanding the somewhat unwieldy expression of equation (32), some insight can be gained about the behavior of $\alpha^{*}$ by looking at, as usual, limiting cases. Consider first the case of perfect equality $(\phi=0.5$ and $\epsilon \rightarrow \infty)$, which reduces equation (32) to

\footnotetext{
${ }^{15}$ The chosen range of aggregate income levels roughly brackets the per capita income levels (in U.S. dollars) of all countries in the world.

${ }^{16}$ The condition $k>1$ ensures that the income distribution frontier cum transfers between the two individuals is negatively sloped.
} 
Table 1. Optimal Values for $\beta$

\begin{tabular}{lcccccc}
\hline \multirow{2}{*}{$\begin{array}{l}\text { Aggregate } \\
\text { income }(2 z)\end{array}$} & \multicolumn{5}{c}{ Degree of relative inequality $(\phi)$} \\
\cline { 2 - 6 } 250 & 0.50 & 0.59 & 0.69 & 0.79 & 0.89 & 0.99 \\
500 & 0.207 & 0.208 & 0.211 & 0.218 & 0.234 & $\ldots$ \\
1,000 & 0.181 & 0.182 & 0.184 & 0.189 & 0.201 & 0.294 \\
2,500 & 0.161 & 0.161 & 0.163 & 0.167 & 0.176 & 0.239 \\
5,000 & 0.140 & 0.141 & 0.142 & 0.145 & 0.151 & 0.193 \\
7,500 & 0.128 & 0.128 & 0.129 & 0.132 & 0.137 & 0.169 \\
10,000 & 0.122 & 0.122 & 0.123 & 0.125 & 0.130 & 0.158 \\
25,000 & 0.117 & 0.118 & 0.119 & 0.121 & 0.125 & 0.151 \\
50,000 & 0.106 & 0.106 & 0.107 & 0.109 & 0.112 & 0.131 \\
100,000 & 0.099 & 0.099 & 0.100 & 0.101 & 0.104 & 0.120 \\
\hline & 0.092 & 0.093 & 0.093 & 0.094 & 0.097 & 0.111 \\
\hline
\end{tabular}




$$
\alpha_{\phi=L}^{*}=2 \cdot(0.5)^{1-\beta^{*}} /(2 z)^{\beta^{*}}=1 / z^{\beta^{*}}<1
$$

Given equations (1) and (9), the average tax rate (for either individual), evaluated at the lower limit for $\phi$, is

$$
a_{\phi=\mathrm{L}}=\alpha_{\phi=\mathrm{L}}^{*}-\rho / z^{\beta^{*}}
$$

Substituting equation (33) into equation (34) yields immediately that $a_{\phi=\mathrm{L}}=0$ at all levels of income, which confirms one's intuition that no tax and transfers are necessary at the point of perfect equality. As regards the behavior of $\alpha_{\phi=L}^{*}$ itself, observe that at the minimum individual pretax income level of $z=e$ (with $\beta^{*}-1$ ), equation (33) implies that $\alpha_{\phi=L}^{*}=1 / e$. In contrast, as $z \rightarrow \infty$ (with $\beta^{*} \rightarrow 0$ ), equation (33) shows that the behavior of $\alpha_{\phi=L}^{*}$ would depend on the behavior of $z^{\beta^{*}}$, which in turn would depend on the relative speeds with which $z$ and $\beta^{*}$ change. This would be ascertainable most conveniently through numerical calculations (as shown below).

Consider next the case of maximum relative inequality $(\phi=1-e / 2 z)$. In this case, one obtains from equation (32)

$$
\alpha_{\phi=\mathrm{U}}^{*}=\frac{2(z-e)+(2-\lambda) \cdot(z-e)^{1-\beta^{*}}-\lambda e^{1-\beta^{*}}-\ln \{(2 z-e) /[2 z \cdot(1-\lambda)-e]\} / \epsilon}{2 z^{*}(2-\lambda)-2 e}
$$

As $z \rightarrow \infty$ (with $\left.\beta^{*} \rightarrow 0\right)^{17}$, an inspection of equation (35) reveals that $\alpha_{\phi=U}^{*}$ depends on a simpler expression:

$$
\lim _{z \rightarrow \infty} \alpha_{\phi=\mathrm{U}}^{*}=\lim _{z \rightarrow \infty}\left[(2-\lambda) \cdot(2 z-e)^{1-\beta^{*}}\right] /[2 z \cdot(2-\lambda)-2 e]
$$

Again, the behavior of $\alpha_{\phi=U}^{*}$ depends in part on the relative speeds with which $z$ and $\beta^{*}$ change. Table 2 provides illustrative numerical calculations for $\alpha^{*}$, assuming the following set of parameter values: $\lambda=0.1$ and $\epsilon=10^{50}$. Hence, the values for $\alpha^{*}$ in Table 2 correspond to the optimal policies of a society with a relatively low efficiency cost of taxation but an extremely high degree of inequality aversion. They reveal two important results. First, $\alpha^{*}$ increases with rising aggregate income levels at all degrees of relative inequality except perfect equality, in which case $\alpha^{*}$ is a constant. Second, for given aggregate income levels, $\alpha^{*}$ rises with increasing degrees of relative inequality - but at a declining rate; it actually declines with further increases in relative inequality from positions of extreme unequal income distribution.

\footnotetext{
${ }^{17}$ It is not necessary to consider the situation of minimum aggregate income, since, as noted earlier, it collapses to the case of perfect equality.
} 
Table 2. Optimal Values for $\alpha 1 /$

\begin{tabular}{lllllll}
\hline \multirow{2}{*}{$\begin{array}{l}\text { Aggregate } \\
\text { income }(2 z)\end{array}$} & 0.50 & 0.59 & 0.69 & 0.79 & 0.89 & 0.99 \\
\cline { 2 - 7 } 250 & 0.368 & 0.520 & 0.633 & 0.707 & 0.746 & $\ldots$ \\
500 & 0.368 & 0.522 & 0.637 & 0.713 & 0.757 & 0.683 \\
1,000 & 0.368 & 0.523 & 0.640 & 0.719 & 0.766 & 0.714 \\
2,500 & 0.368 & 0.524 & 0.643 & 0.724 & 0.775 & 0.742 \\
5,000 & 0.368 & 0.525 & 0.645 & 0.727 & 0.780 & 0.758 \\
7,500 & 0.368 & 0.526 & 0.646 & 0.729 & 0.783 & 0.766 \\
10,000 & 0.368 & 0.526 & 0.647 & 0.730 & 0.785 & 0.771 \\
25,000 & 0.368 & 0.527 & 0.648 & 0.733 & 0.789 & 0.785 \\
50,000 & 0.368 & 0.527 & 0.649 & 0.735 & 0.792 & 0.793 \\
100,000 & 0.368 & 0.528 & 0.650 & 0.736 & 0.795 & 0.800 \\
& & & & & & \\
\hline
\end{tabular}

1/ Assumed set of parameter values: $\lambda=0.1 ; \epsilon=10^{50}$. 


\section{Optimal tax rates}

Based on the optimal values for $\beta$ and $\alpha$, given respectively in Table 1 and Table 2, the optimal average and marginal tax rates for the two individuals can be derived in a straightforward manner - through the use of equation (1) and equation (4) - for different combinations of aggregate pretax income levels and degrees of relative inequality. These calculations are reported in Table 3 for the average tax rates and in Table 4 for the marginal tax rates. Table 3 confirms the earlier observation that the average tax rates for both individuals are zero when there is perfect equality $(\phi=0.5)$. At all other degrees of relative inequality and aggregate income levels, however, the average tax rate of individual $A$ exceeds that of individual $B$, thus indicating that the optimal tax structure is progressive (in the average sense) everywhere except at the point of perfect equality. More importantly, Table 3 reveals that the difference between the average tax rates of the two individuals rises with higher degrees of relative inequality (for a given aggregate income level) and falls with higher levels of aggregate income (for a given degree of relative inequality).

Exactly the same qualitative observations about progressivity (in the marginal sense) can be made about the marginal tax rates shown in Table 4: the marginal tax rate of individual $A$ exceeds that of individual $B$ everywhere except at the point of perfect equality, and that this difference rises with higher degrees of relative inequality (for a given aggregate income level) and falls with higher levels of aggregate income (for a given degree of relative inequality). While not shown in Table 3 and Table 4, the difference between the tax rates of the two individuals, either in average or marginal terms, goes to zero (at all degrees of relative inequality) as the aggregate income level goes to infinity. ${ }^{18}$

\footnotetext{
${ }^{18}$ It is perhaps useful to note here that the most celebrated result of the optimal income tax literature - the optimal marginal tax rates at both ends of the income scale are zero (see, in particular, Seade (1977))--does not apply here, due to the presence of targeted transfers to the poor. The intuition behind the conventional outcome of zero marginal rate at the top is that reducing the top marginal rate to zero makes the top person (individual $A$ in the present setup) better off without affecting the welfare of any other person. With targeted transfers, however, any additional revenue raised from the top person (by not letting his marginal rate go to zero) will make someone else (individual $B$ ) better off, as long as the revenue so raised is greater than the associated efficiency cost of the tax. Turning to the bottom end, the optimal marginal tax rate there is also not zero because of the particular functional form of the tax function (equation (1)) that has been assumed in the present model, which does not allow for any inflection point to exist. Since both individuals must face the same two (optimized) parameters $-\alpha$ and $\beta$ - of the function, the outcome is one where $B$ would also face a positive marginal tax rate (albeit lower than $A$ 's). Of course, if $\alpha$ and $\beta$ could be optimized separately for the two individuals, then there would be no reason to impose a $\operatorname{tax}$ on $B$ at all. But this would be a most uninteresting problem since, if the tax function could be made individualspecific, all that is needed would be a lump-sum tax on $A$.
} 
Table 3. Average Tax Rates

(Low efficiency cost and high inequality aversion) 1/

\begin{tabular}{|c|c|c|c|c|c|c|}
\hline \multirow{2}{*}{$\begin{array}{l}\text { Aggregate } \\
\text { income }(2 z)\end{array}$} & \multicolumn{6}{|c|}{ Degree of relative inequality $(\phi)$} \\
\hline & 0.50 & 0.59 & 0.69 & 0.79 & 0.89 & 0.99 \\
\hline & \multicolumn{6}{|c|}{ Individual $A$} \\
\hline 250 & 0.000 & 0.166 & 0.295 & 0.390 & 0.463 & $\ldots$ \\
\hline 500 & 0.000 & 0.166 & 0.296 & 0.391 & 0.463 & 0.521 \\
\hline 1,000 & 0.000 & 0.166 & 0.296 & 0.391 & 0.463 & 0.521 \\
\hline 2,500 & 0.000 & 0.166 & 0.296 & 0.391 & 0.464 & 0.521 \\
\hline 5,000 & 0.000 & 0.166 & 0.296 & 0.391 & 0.464 & 0.521 \\
\hline 7,500 & 0.000 & 0.166 & 0.296 & 0.391 & 0.464 & 0.521 \\
\hline 10,000 & 0.000 & 0.166 & 0.296 & 0.391 & 0.464 & 0.521 \\
\hline 25,000 & 0.000 & 0.166 & 0.296 & 0.391 & 0.464 & 0.521 \\
\hline 50,000 & 0.000 & 0.166 & 0.296 & 0.391 & 0.464 & 0.521 \\
\hline \multirow[t]{2}{*}{100,000} & 0.000 & 0.166 & 0.296 & 0.391 & 0.464 & 0.521 \\
\hline & \multicolumn{6}{|c|}{ Individual $B$} \\
\hline 250 & 0.000 & 0.138 & 0.233 & 0.285 & 0.285 & $\ldots$ \\
\hline 500 & 0.000 & 0.141 & 0.241 & 0.299 & 0.310 & 0.059 \\
\hline 1,000 & 0.000 & 0.144 & 0.248 & 0.309 & 0.329 & 0.137 \\
\hline 2,500 & 0.000 & 0.147 & 0.254 & 0.320 & 0.348 & 0.205 \\
\hline 5,000 & 0.000 & 0.149 & 0.258 & 0.327 & 0.359 & 0.242 \\
\hline 7,500 & 0.000 & 0.150 & 0.260 & 0.330 & 0.364 & 0.260 \\
\hline 10,000 & 0.000 & 0.150 & 0.261 & 0.332 & 0.368 & 0.272 \\
\hline 25,000 & 0.000 & 0.152 & 0.265 & 0.338 & 0.378 & 0.302 \\
\hline 50,000 & 0.000 & 0.153 & 0.267 & 0.342 & 0.384 & 0.320 \\
\hline \multirow[t]{2}{*}{100,000} & 0.000 & 0.154 & 0.269 & 0.345 & 0.389 & 0.336 \\
\hline & \multicolumn{6}{|c|}{ Excess of $A$ over $B$} \\
\hline 250 & 0.000 & 0.028 & 0.062 & 0.106 & 0.178 & $\ldots$ \\
\hline 500 & 0.000 & 0.024 & 0.054 & 0.092 & 0.153 & 0.462 \\
\hline 1,000 & 0.000 & 0.022 & 0.048 & 0.081 & 0.135 & 0.384 \\
\hline 2,500 & 0.000 & 0.019 & 0.042 & 0.070 & 0.116 & 0.316 \\
\hline 5,000 & 0.000 & 0.017 & 0.038 & 0.064 & 0.105 & 0.279 \\
\hline 7,500 & 0.000 & 0.016 & 0.036 & 0.061 & 0.099 & 0.261 \\
\hline 10,000 & 0.000 & 0.016 & 0.035 & 0.059 & 0.096 & 0.250 \\
\hline 25,000 & 0.000 & 0.014 & 0.031 & 0.053 & 0.086 & 0.219 \\
\hline 50,000 & 0.000 & 0.013 & 0.029 & 0.049 & 0.080 & 0.201 \\
\hline 100,000 & 0.000 & 0.012 & 0.027 & 0.046 & 0.074 & 0.186 \\
\hline
\end{tabular}

1/ Assumed set of parameter values: $\lambda=0.1 ; \epsilon=10^{50}$. 
Table 4. Marginal Tax Rates

(Low efficiency cost and high inequality aversion) 1/

\begin{tabular}{|c|c|c|c|c|c|c|}
\hline \multirow{2}{*}{$\begin{array}{l}\text { Aggregate } \\
\text { income }(2 z) \\
\end{array}$} & \multicolumn{6}{|c|}{ Degree of relative inequality $(\phi)$} \\
\hline & 0.50 & 0.59 & 0.69 & 0.79 & 0.89 & 0.99 \\
\hline & \multicolumn{6}{|c|}{ Individual $A$} \\
\hline 250 & 0.076 & 0.239 & 0.367 & 0.459 & 0.529 & \\
\hline 500 & 0.067 & 0.230 & 0.358 & 0.452 & 0.522 & 0.569 \\
\hline 1,000 & 0.059 & 0.223 & 0.352 & 0.446 & 0.517 & 0.567 \\
\hline 2,500 & 0.052 & 0.216 & 0.345 & 0.439 & 0.511 & 0.564 \\
\hline 5,000 & 0.047 & 0.212 & 0.341 & 0.435 & 0.507 & 0.561 \\
\hline 7,500 & 0.045 & 0.210 & 0.339 & 0.433 & 0.505 & 0.560 \\
\hline 10,000 & 0.043 & 0.208 & 0.338 & 0.432 & 0.504 & 0.559 \\
\hline 25,000 & 0.039 & 0.204 & 0.334 & 0.428 & 0.500 & 0.556 \\
\hline 50,000 & 0.036 & 0.202 & 0.331 & 0.426 & 0.498 & 0.554 \\
\hline \multirow[t]{2}{*}{100,000} & 0.034 & 0.200 & 0.329 & 0.424 & 0.496 & 0.552 \\
\hline & \multicolumn{6}{|c|}{ Individual $B$} \\
\hline 250 & 0.076 & 0.217 & 0.318 & 0.377 & 0.393 & $\ldots$ \\
\hline 500 & 0.067 & 0.210 & 0.314 & 0.377 & 0.400 & 0.242 \\
\hline 1,000 & 0.059 & 0.205 & 0.312 & 0.378 & 0.406 & 0.274 \\
\hline 2,500 & 0.052 & 0.200 & 0.309 & 0.379 & 0.412 & 0.309 \\
\hline 5,000 & 0.047 & 0.197 & 0.308 & 0.380 & 0.416 & 0.330 \\
\hline 7,500 & 0.045 & 0.196 & 0.307 & 0.380 & 0.419 & 0.340 \\
\hline 10,000 & 0.043 & 0.195 & 0.307 & 0.380 & 0.420 & 0.347 \\
\hline 25,000 & 0.039 & 0.192 & 0.306 & 0.381 & 0.424 & 0.365 \\
\hline 50,000 & 0.036 & 0.190 & 0.305 & 0.382 & 0.426 & 0.377 \\
\hline \multirow[t]{2}{*}{100,000} & 0.034 & 0.188 & 0.304 & 0.382 & 0.429 & 0.387 \\
\hline & \multicolumn{6}{|c|}{ Excess of $A$ over $B$} \\
\hline 250 & 0.000 & 0.022 & 0.049 & 0.083 & 0.136 & $\ldots$ \\
\hline 500 & 0.000 & 0.020 & 0.044 & 0.075 & 0.123 & 0.326 \\
\hline 1,000 & 0.000 & 0.018 & 0.040 & 0.068 & 0.111 & 0.293 \\
\hline 2,500 & 0.000 & 0.016 & 0.036 & 0.060 & 0.098 & 0.255 \\
\hline 5,000 & 0.000 & 0.015 & 0.033 & 0.056 & 0.091 & 0.232 \\
\hline 7,500 & 0.000 & 0.014 & 0.032 & 0.053 & 0.087 & 0.220 \\
\hline 10,000 & 0.000 & 0.014 & 0.031 & 0.052 & 0.084 & 0.212 \\
\hline 25,000 & 0.000 & 0.013 & 0.028 & 0.047 & 0.076 & 0.191 \\
\hline 50,000 & 0.000 & 0.012 & 0.026 & 0.044 & 0.072 & 0.177 \\
\hline 100,000 & 0.000 & 0.011 & 0.025 & 0.042 & 0.067 & 0.165 \\
\hline
\end{tabular}

1/ Assumed set of parameter values: $\lambda=0.1 ; \epsilon=10^{50}$. 
The fundamental implications that can be drawn from Table 3 and Table 4 are as follows. First, for a given level of aggregate pretax income, a progressive tax becomes more desirable than a proportional tax as relative inequality rises, because the former is more effective than the latter in raising the needed revenue to finance the desired transfers to reduce inequality. Putting it differently, since by definition a progressive tax imposes a higher tax burden on the rich than on the poor, any desired degree of inequality reduction could be achieved with less required tax revenue to effect the transfers-and hence with less efficiency cost to society-under a progressive than a proportional tax function. Second, for any given degree of relative inequality, the optimal tax function tends increasingly towards proportionality as the level of aggregate pretax income rises. An intuitive explanation for this is that, as the income levels for both the rich and poor rise, an increasing amount of revenue can be raised with a relatively low, even if uniform, tax rate. Hence, the inherent advantage of employing a progressive tax function for revenue-raising purposes diminishes with rising levels of income. In the limit, the optimal tax function would be proportional, irrespective of the degree of relative inequality.

The tendency, from the perspective of either individual, for the degree of progressivity to decline with rising income levels - whether this rise originates from a changing level of aggregate income or degree of relative inequality — can be looked at from a different angle. As discussed earlier, one concept of progressivity is the $A R P$. As defined in equation (7), however, the $A R P$ is not unit-free. Lambert (1993) has proposed a modified $A R P$ (call it $M A R P$ ), which is unit-free, by multiplying the $A R P$ by the relevant income level. From equation (7), it is easily seen that this procedure results in the $M A R P$ being simply a measure of the excess of the marginal tax rate over the average tax rate at a particular income level:

$$
M A R P \equiv A R P \cdot y=m-a .
$$

Table 5 provides the $M A R P$ calculations, based on Table 3 and Table 4 . As can be seen, the $M A R P$ declines with rising aggregate income levels for both individuals. Somewhat surprising at first glance, however, is that, for a given level of aggregate income, a higher degree of relative inequality leads to a lower $M A R P$ for individual $A$ (as expected) but a higher $M A R P$ for individual $B$. This puzzle is resolved once note is taken of the fact that, for individual $B$, a higher degree of relative inequality implies a lower level of income.

\section{Sensitivity analyses}

Tables 3-5 indicate that, at low to moderate aggregate income levels, the optimal degree of tax progressivity could be quite pronounced as relative inequality becomes more acute. For example, the excess of the average (marginal) tax rate of individual $A$ over that of individual $B$ could be as high as $46(33)$ percentage points. These calculations are based, however, on the assumption of a relatively low efficiency cost of taxation and an extremely high degree of inequality aversion. Tables 6-7 provide numerical calculations of optimal average and marginal tax rates for the case of a very high efficiency cost of taxation $(\lambda=0.4)$ while maintaining the same high degree of inequality aversion as that underlies Tables $3-4$. Since 
Table 5. Modified Average Rate Progression

(Low efficiency cost and high inequality aversion) 1/

\begin{tabular}{|c|c|c|c|c|c|c|}
\hline \multirow{2}{*}{$\begin{array}{l}\text { Aggregate } \\
\text { income }(2 z)\end{array}$} & \multicolumn{6}{|c|}{ Degree of relative inequality $(\phi)$} \\
\hline & 0.50 & 0.59 & 0.69 & 0.79 & 0.89 & 0.99 \\
\hline & \multicolumn{6}{|c|}{ Individual $A$} \\
\hline 250 & 0.076 & 0.074 & 0.071 & 0.069 & 0.066 & \\
\hline 500 & 0.067 & 0.065 & 0.063 & 0.061 & 0.059 & 0.047 \\
\hline 1,000 & 0.059 & 0.058 & 0.056 & 0.055 & 0.053 & 0.046 \\
\hline 2,500 & 0.052 & 0.050 & 0.049 & 0.048 & 0.047 & 0.043 \\
\hline 5,000 & 0.047 & 0.046 & 0.045 & 0.044 & 0.043 & 0.040 \\
\hline 7,500 & 0.045 & 0.044 & 0.043 & 0.042 & 0.041 & 0.039 \\
\hline 10,000 & 0.043 & 0.042 & 0.042 & 0.041 & 0.040 & 0.038 \\
\hline 25,000 & 0.039 & 0.038 & 0.038 & 0.037 & 0.037 & 0.035 \\
\hline 50,000 & 0.036 & 0.036 & 0.035 & 0.035 & 0.034 & 0.033 \\
\hline \multirow[t]{2}{*}{100,000} & 0.034 & 0.033 & 0.033 & 0.033 & 0.032 & 0.031 \\
\hline & \multicolumn{6}{|c|}{ Individual $B$} \\
\hline 250 & 0.076 & 0.079 & 0.084 & 0.092 & 0.108 & $\ldots$ \\
\hline 500 & 0.067 & 0.069 & 0.073 & 0.078 & 0.090 & 0.183 \\
\hline 1,000 & 0.059 & 0.061 & 0.064 & 0.068 & 0.077 & 0.138 \\
\hline 2,500 & 0.052 & 0.053 & 0.055 & 0.058 & 0.065 & 0.104 \\
\hline 5,000 & 0.047 & 0.048 & 0.050 & 0.053 & 0.058 & 0.087 \\
\hline 7,500 & 0.045 & 0.046 & 0.047 & 0.050 & 0.054 & 0.080 \\
\hline 10,000 & 0.043 & 0.044 & 0.046 & 0.048 & 0.052 & 0.075 \\
\hline 25,000 & 0.039 & 0.040 & 0.041 & 0.043 & 0.046 & 0.064 \\
\hline 50,000 & 0.036 & 0.037 & 0.038 & 0.040 & 0.042 & 0.057 \\
\hline 100,000 & 0.034 & 0.035 & 0.036 & 0.037 & 0.039 & 0.052 \\
\hline
\end{tabular}

1/ Assumed set of parameter values: $\lambda=0.1 ; \epsilon=10^{50}$. 
Table 6. Average Tax Rates

(High efficiency cost and high inequality aversion) 1/

\begin{tabular}{|c|c|c|c|c|c|c|}
\hline \multirow{2}{*}{$\begin{array}{l}\text { Aggregate } \\
\text { income }(2 z)\end{array}$} & \multicolumn{6}{|c|}{ Degree of relative inequality $(\phi)$} \\
\hline & 0.50 & 0.59 & 0.69 & 0.79 & 0.89 & 0.99 \\
\hline & \multicolumn{6}{|c|}{ Individual $A$} \\
\hline 250 & 0.000 & 0.225 & 0.380 & 0.484 & 0.560 & \\
\hline 500 & 0.000 & 0.226 & 0.381 & 0.485 & 0.560 & 0.619 \\
\hline 1,000 & 0.000 & 0.226 & 0.382 & 0.486 & 0.561 & 0.619 \\
\hline 2,500 & 0.000 & 0.227 & 0.382 & 0.487 & 0.562 & 0.619 \\
\hline 5,000 & 0.000 & 0.227 & 0.383 & 0.487 & 0.562 & 0.620 \\
\hline 7,500 & 0.000 & 0.227 & 0.383 & 0.487 & 0.562 & 0.620 \\
\hline 10,000 & 0.000 & 0.227 & 0.383 & 0.487 & 0.562 & 0.620 \\
\hline 25,000 & 0.000 & 0.228 & 0.384 & 0.488 & 0.562 & 0.620 \\
\hline 50,000 & 0.000 & 0.228 & 0.384 & 0.488 & 0.563 & 0.620 \\
\hline \multirow[t]{2}{*}{100,000} & 0.000 & 0.228 & 0.383 & 0.488 & 0.563 & 0.620 \\
\hline & \multicolumn{6}{|c|}{ Individual $B$} \\
\hline 250 & 0.000 & 0.197 & 0.318 & 0.378 & 0.381 & \\
\hline 500 & 0.000 & 0.201 & 0.327 & 0.393 & 0.407 & 0.157 \\
\hline 1,000 & 0.000 & 0.205 & 0.334 & 0.404 & 0.426 & 0.235 \\
\hline 2,500 & 0.000 & 0.208 & 0.341 & 0.416 & 0.446 & 0.304 \\
\hline 5,000 & 0.000 & 0.210 & 0.345 & 0.423 & 0.457 & 0.341 \\
\hline 7,500 & 0.000 & 0.211 & 0.347 & 0.426 & 0.463 & 0.359 \\
\hline 10,000 & 0.000 & 0.212 & 0.348 & 0.429 & 0.466 & 0.370 \\
\hline 25,000 & 0.000 & 0.214 & 0.352 & 0.435 & 0.476 & 0.400 \\
\hline 50,000 & 0.000 & 0.215 & 0.355 & 0.439 & 0.483 & 0.419 \\
\hline \multirow[t]{2}{*}{100,000} & 0.000 & 0.216 & 0.357 & 0.442 & 0.488 & 0.434 \\
\hline & \multicolumn{6}{|c|}{ Excess of $A$ over $B$} \\
\hline 250 & 0.000 & 0.028 & 0.062 & 0.106 & 0.178 & $\ldots$ \\
\hline 500 & 0.000 & 0.024 & 0.054 & 0.092 & 0.153 & 0.462 \\
\hline 1,000 & 0.000 & 0.022 & 0.048 & 0.081 & 0.135 & 0.384 \\
\hline 2,500 & 0.000 & 0.019 & 0.042 & 0.070 & 0.116 & 0.316 \\
\hline 5,000 & 0.000 & 0.017 & 0.038 & 0.064 & 0.105 & 0.279 \\
\hline 7,500 & 0.000 & 0.016 & 0.036 & 0.061 & 0.099 & 0.261 \\
\hline 10,000 & 0.000 & 0.016 & 0.035 & 0.059 & 0.096 & 0.250 \\
\hline 25,000 & 0.000 & 0.014 & 0.031 & 0.053 & 0.086 & 0.219 \\
\hline 50,000 & 0.000 & 0.013 & 0.029 & 0.049 & 0.080 & 0.201 \\
\hline 100,000 & 0.000 & 0.012 & 0.027 & 0.046 & 0.074 & 0.186 \\
\hline
\end{tabular}

1/ Assumed set of parameter values: $\lambda=0.4 ; \epsilon=10^{50}$. 
Table 7. Marginal Tax Rates

(High efficiency cost and high inequality aversion) 1/

\begin{tabular}{|c|c|c|c|c|c|c|}
\hline \multirow{2}{*}{$\begin{array}{l}\text { Aggregate } \\
\text { income }(2 z) \\
\end{array}$} & \multicolumn{6}{|c|}{ Degree of relative inequality $(\phi)$} \\
\hline & 0.50 & 0.59 & 0.69 & 0.79 & 0.89 & 0.99 \\
\hline & \multicolumn{6}{|c|}{ Individual $A$} \\
\hline 250 & 0.076 & 0.299 & 0.451 & 0.553 & 0.626 & $\ldots$ \\
\hline 500 & 0.067 & 0.290 & 0.444 & 0.546 & 0.619 & 0.667 \\
\hline 1,000 & 0.059 & 0.284 & 0.438 & 0.541 & 0.614 & 0.665 \\
\hline 2,500 & 0.052 & 0.277 & 0.432 & 0.535 & 0.609 & 0.662 \\
\hline 5,000 & 0.047 & 0.273 & 0.428 & 0.531 & 0.605 & 0.660 \\
\hline 7,500 & 0.045 & 0.271 & 0.426 & 0.529 & 0.603 & 0.658 \\
\hline 10,000 & 0.043 & 0.270 & 0.425 & 0.528 & 0.602 & 0.657 \\
\hline 25,000 & 0.039 & 0.266 & 0.421 & 0.525 & 0.599 & 0.654 \\
\hline 50,000 & 0.036 & 0.264 & 0.419 & 0.523 & 0.597 & 0.653 \\
\hline \multirow[t]{2}{*}{100,000} & 0.034 & 0.262 & 0.417 & 0.521 & 0.595 & 0.651 \\
\hline & \multicolumn{6}{|c|}{ Individual $B$} \\
\hline 250 & 0.076 & 0.276 & 0.402 & 0.470 & 0.489 & $\ldots$ \\
\hline 500 & 0.067 & 0.270 & 0.400 & 0.471 & 0.497 & 0.340 \\
\hline 1,000 & 0.059 & 0.266 & 0.398 & 0.473 & 0.503 & 0.373 \\
\hline 2,500 & 0.052 & 0.261 & 0.396 & 0.474 & 0.510 & 0.407 \\
\hline 5,000 & 0.047 & 0.258 & 0.395 & 0.476 & 0.515 & 0.428 \\
\hline 7,500 & 0.045 & 0.257 & 0.394 & 0.476 & 0.517 & 0.438 \\
\hline 10,000 & 0.043 & 0.256 & 0.394 & 0.477 & 0.518 & 0.445 \\
\hline 25,000 & 0.039 & 0.253 & 0.393 & 0.478 & 0.523 & 0.464 \\
\hline 50,000 & 0.036 & 0.252 & 0.393 & 0.479 & 0.525 & 0.476 \\
\hline \multirow[t]{2}{*}{100,000} & 0.034 & 0.250 & 0.392 & 0.479 & 0.528 & 0.486 \\
\hline & \multicolumn{6}{|c|}{ Excess of $A$ over $B$} \\
\hline 250 & 0.000 & 0.022 & 0.049 & 0.083 & 0.136 & $\ldots$ \\
\hline 500 & 0.000 & 0.020 & 0.044 & 0.075 & 0.123 & 0.326 \\
\hline 1,000 & 0.000 & 0.018 & 0.040 & 0.068 & 0.111 & 0.293 \\
\hline 2,500 & 0.000 & 0.016 & 0.036 & 0.060 & 0.098 & 0.255 \\
\hline 5,000 & 0.000 & 0.015 & 0.033 & 0.056 & 0.091 & 0.232 \\
\hline 7,500 & 0.000 & 0.014 & 0.032 & 0.053 & 0.087 & 0.220 \\
\hline 10,000 & 0.000 & 0.014 & 0.031 & 0.052 & 0.084 & 0.212 \\
\hline 25,000 & 0.000 & 0.013 & 0.028 & 0.047 & 0.076 & 0.191 \\
\hline 50,000 & 0.000 & 0.012 & 0.026 & 0.044 & 0.072 & 0.177 \\
\hline 100,000 & 0.000 & 0.011 & 0.025 & 0.042 & 0.067 & 0.165 \\
\hline
\end{tabular}

1/ Assumed set of parameter values: $\lambda=0.4 ; \epsilon=10^{50}$. 
higher efficiency costs of taxation would require higher tax rates to effect any given amount of redistributive transfers, the optimal tax rates for both individuals, in either average or marginal terms, are now higher than the previous case. Notwithstanding this outcome, Tables 6-7 show that the difference between the two individuals' average or marginal tax rates remains exactly as before for every combination of aggregate income level and degree of relative inequality. This is due, of course, to the fact that a change in $\lambda$ affects only $\alpha^{*}$ but not $\beta^{*}$. It is also noteworthy to point out that, even in this case of very high efficiency cost of taxation coupled with extreme inequality aversion, the optimal marginal tax rate does not exceed 67 percent.

Tables 8-9 provide numerical calculations for the case of the same high efficiency cost of taxation that underlies Tables 6-7, i.e., $\lambda=0.4$, but in this instance combined with a low inequality aversion $(\epsilon=0.01)$. As expected, the reduction in inequality aversion leads to a lowering of both average and marginal tax rates for both individuals at all degrees of relative inequality, but this impact is most significant at low to moderate aggregate income levels. The impact tends to fade as the aggregate income level is increased, which follows from the earlier discussion of how changes in $\epsilon$ would affect $\alpha^{*}$. Since, again, only $\alpha^{*}$ and not $\beta^{*}$ is affected by the change in $\epsilon$, the reduction in inequality aversion leaves the difference in the tax rates between the two individuals unchanged, except in those instances where their tax rates are reduced to zero. ${ }^{19}$

The numerical calculations discussed above reflect the important and fundamental implication of the fact that $\beta^{*}$-which determines the optimal progressivity of the tax structure-depends only on the degree of relative inequality in income distribution; it depends on neither society's inequality aversion nor the efficiency cost of taxation. These latter considerations affect instead the tax parameter $\alpha^{*}$ that is associated with the optimal size of redistributive transfers.

\section{CONCLUding REMARKS}

This paper has derived and discussed the nature of optimal redistributive tax and transfer policies within the context of a simple analytical framework where an income tax, which could be either proportional or progressive, is used to effect (perfectly) targeted transfers from the rich to the poor. The key analytical point of the paper is that a progressive income tax is more effective than a proportional income tax in raising revenue. Hence, if tax revenue is used to finance transfers to reduce inequality, the stronger would be the case for progressive income taxation, the more unequal is the distribution of income. This justification for tax progressivity in financing government transfer programs is largely overlooked in the literature on optimal income taxation.

\footnotetext{
${ }^{19}$ Although not shown explicitly, it is easy to confirm that the $M A R P$ under the different combinations of $\lambda$ and $\epsilon$ also remains unchanged from that reported in Table 5 .
} 
Table 8. Average Tax Rates

(High efficiency cost and low inequality aversion) $1 /$

\begin{tabular}{|c|c|c|c|c|c|c|}
\hline \multirow{2}{*}{$\begin{array}{l}\text { Aggregate } \\
\text { income }(2 z)\end{array}$} & \multicolumn{6}{|c|}{ Degree of relative inequality $(\phi)$} \\
\hline & 0.50 & 0.59 & 0.69 & 0.79 & 0.89 & 0.99 \\
\hline & \multicolumn{6}{|c|}{ Individual $A$} \\
\hline 250 & 0.000 & 0.000 & 0.026 & 0.245 & 0.387 & $\ldots$ \\
\hline 500 & 0.000 & 0.000 & 0.204 & 0.365 & 0.474 & 0.554 \\
\hline 1,000 & 0.000 & 0.081 & 0.293 & 0.426 & 0.518 & 0.587 \\
\hline 2,500 & 0.000 & 0.169 & 0.347 & 0.463 & 0.544 & 0.606 \\
\hline 5,000 & 0.000 & 0.198 & 0.365 & 0.475 & 0.553 & 0.613 \\
\hline 7,500 & 0.000 & 0.208 & 0.371 & 0.479 & 0.556 & 0.615 \\
\hline 10,000 & 0.000 & 0.213 & 0.374 & 0.481 & 0.558 & 0.616 \\
\hline 25,000 & 0.000 & 0.222 & 0.380 & 0.485 & 0.561 & 0.618 \\
\hline 50,000 & 0.000 & 0.225 & 0.382 & 0.487 & 0.562 & 0.619 \\
\hline \multirow[t]{2}{*}{100,000} & 0.000 & 0.227 & 0.383 & 0.488 & 0.562 & 0.619 \\
\hline & \multicolumn{6}{|c|}{ Individual $B$} \\
\hline 250 & 0.000 & 0.000 & 0.000 & 0.139 & 0.208 & $\ldots$ \\
\hline 500 & 0.000 & 0.000 & 0.150 & 0.273 & 0.321 & 0.092 \\
\hline 1,000 & 0.000 & 0.059 & 0.245 & 0.345 & 0.383 & 0.202 \\
\hline 2,500 & 0.000 & 0.150 & 0.305 & 0.392 & 0.428 & 0.290 \\
\hline 5,000 & 0.000 & 0.181 & 0.327 & 0.411 & 0.448 & 0.334 \\
\hline 7,500 & 0.000 & 0.192 & 0.335 & 0.418 & 0.457 & 0.354 \\
\hline 10,000 & 0.000 & 0.197 & 0.340 & 0.423 & 0.462 & 0.367 \\
\hline 25,000 & 0.000 & 0.208 & 0.349 & 0.433 & 0.475 & 0.399 \\
\hline 50,000 & 0.000 & 0.212 & 0.353 & 0.438 & 0.482 & 0.418 \\
\hline \multirow[t]{2}{*}{100,000} & 0.000 & 0.214 & 0.356 & 0.442 & 0.488 & 0.434 \\
\hline & \multicolumn{6}{|c|}{ Excess of $A$ over $B$} \\
\hline 250 & 0.000 & 0.000 & 0.026 & 0.106 & 0.178 & $\ldots$ \\
\hline 500 & 0.000 & 0.000 & 0.054 & 0.092 & 0.153 & 0.462 \\
\hline 1,000 & 0.000 & 0.022 & 0.048 & 0.081 & 0.135 & 0.384 \\
\hline 2,500 & 0.000 & 0.019 & 0.042 & 0.070 & 0.116 & 0.316 \\
\hline 5,000 & 0.000 & 0.017 & 0.038 & 0.064 & 0.105 & 0.279 \\
\hline 7,500 & 0.000 & 0.016 & 0.036 & 0.061 & 0.099 & 0.261 \\
\hline 10,000 & 0.000 & 0.016 & 0.035 & 0.059 & 0.096 & 0.250 \\
\hline 25,000 & 0.000 & 0.014 & 0.031 & 0.053 & 0.086 & 0.219 \\
\hline 50,000 & 0.000 & 0.013 & 0.029 & 0.049 & 0.080 & 0.201 \\
\hline 100,000 & 0.000 & 0.012 & 0.027 & 0.046 & 0.074 & 0.186 \\
\hline
\end{tabular}

1/ Assumed set of parameter values: $\lambda=0.4 ; \epsilon=0.01$. 
Table 9. Marginal Tax Rates

(High efficiency cost and low inequality aversion) 1/

\begin{tabular}{|c|c|c|c|c|c|c|}
\hline \multirow{2}{*}{$\begin{array}{l}\text { Aggregate } \\
\text { income }(2 z)\end{array}$} & \multicolumn{6}{|c|}{ Degree of relative inequality $(\phi)$} \\
\hline & 0.50 & 0.59 & 0.69 & 0.79 & 0.89 & 0.99 \\
\hline & \multicolumn{6}{|c|}{ Individual $A$} \\
\hline 250 & 0.000 & 0.000 & 0.097 & 0.314 & 0.453 & $\ldots$ \\
\hline 500 & 0.000 & 0.000 & 0.267 & 0.426 & 0.533 & 0.601 \\
\hline 1,000 & 0.000 & 0.139 & 0.349 & 0.481 & 0.571 & 0.633 \\
\hline 2,500 & 0.000 & 0.219 & 0.396 & 0.511 & 0.591 & 0.649 \\
\hline 5,000 & 0.000 & 0.244 & 0.410 & 0.519 & 0.597 & 0.653 \\
\hline 7,500 & 0.009 & 0.252 & 0.414 & 0.521 & 0.598 & 0.654 \\
\hline 10,000 & 0.016 & 0.255 & 0.416 & 0.522 & 0.598 & 0.654 \\
\hline 25,000 & 0.028 & 0.260 & 0.418 & 0.522 & 0.597 & 0.653 \\
\hline 50,000 & 0.031 & 0.261 & 0.417 & 0.522 & 0.596 & 0.652 \\
\hline \multirow[t]{2}{*}{100,000} & 0.031 & 0.260 & 0.416 & 0.520 & 0.595 & 0.650 \\
\hline & \multicolumn{6}{|c|}{ Individual $B$} \\
\hline 250 & 0.000 & 0.000 & 0.048 & 0.231 & 0.316 & $\ldots$. \\
\hline 500 & 0.000 & 0.000 & 0.223 & 0.352 & 0.410 & 0.275 \\
\hline 1,000 & 0.000 & 0.120 & 0.309 & 0.413 & 0.460 & 0.340 \\
\hline 2,500 & 0.000 & 0.203 & 0.361 & 0.451 & 0.493 & 0.394 \\
\hline 5,000 & 0.000 & 0.229 & 0.377 & 0.464 & 0.506 & 0.421 \\
\hline 7,500 & 0.009 & 0.237 & 0.383 & 0.468 & 0.511 & 0.434 \\
\hline 10,000 & 0.016 & 0.241 & 0.385 & 0.471 & 0.514 & 0.442 \\
\hline 25,000 & 0.028 & 0.248 & 0.390 & 0.475 & 0.521 & 0.463 \\
\hline 50,000 & 0.031 & 0.249 & 0.391 & 0.477 & 0.524 & 0.475 \\
\hline \multirow[t]{2}{*}{100,000} & 0.031 & 0.249 & 0.392 & 0.479 & 0.527 & 0.485 \\
\hline & \multicolumn{6}{|c|}{ Excess of $A$ over $B$} \\
\hline 250 & 0.000 & 0.000 & 0.049 & 0.083 & 0.136 & $\ldots$ \\
\hline 500 & 0.000 & 0.000 & 0.044 & 0.075 & 0.123 & 0.326 \\
\hline 1,000 & 0.000 & 0.018 & 0.040 & 0.068 & 0.111 & 0.293 \\
\hline 2,500 & 0.000 & 0.016 & 0.036 & 0.060 & 0.098 & 0.255 \\
\hline 5,000 & 0.000 & 0.015 & 0.033 & 0.056 & 0.091 & 0.232 \\
\hline 7,500 & 0.000 & 0.014 & 0.032 & 0.053 & 0.087 & 0.220 \\
\hline 10,000 & 0.000 & 0.014 & 0.031 & 0.052 & 0.084 & 0.212 \\
\hline 25,000 & 0.000 & 0.013 & 0.028 & 0.047 & 0.076 & 0.191 \\
\hline 50,000 & 0.000 & 0.012 & 0.026 & 0.044 & 0.072 & 0.177 \\
\hline 100,000 & 0.000 & 0.011 & 0.025 & 0.042 & 0.067 & 0.165 \\
\hline
\end{tabular}

1/ Assumed set of parameter values: $\lambda=0.4 ; \epsilon=0.01$. 
The specific model of the paper permits a clear separation of the revenue-raising and redistributive functions of different parameters of an income tax. While this separation would not, in general, be possible in a more general model, the policy implications of the paper's basic result would remain valid. The optimal financing of transfers, even if they could be perfectly targeted, would generally entail a tax function having some degree of progressivity. The need for this progressivity lessens, however, as income levels rise for both the rich and the poor (for a given degree of relative inequality). This is because the inherent relative advantage of a progressive tax for revenue-raising purposes diminishes at high income levels, since at such income levels a significant amount of revenue can be raised with a relatively low, even if uniform, tax rate.

While the above result has the implication that the case for progressive taxation is stronger in poor than in rich countries, it is not the intention of the paper to endorse it unconditionally as a policy prescription, since many legitimate considerations against progressive taxation have been ignored in the analysis. Instead, the real purpose of the paper is to underscore the theoretical point that, in designing equity-driven expenditure programs, the potential useful role of progressive taxation-for raising revenue and not for lessening inequality directly-should not be ignored, especially at low levels of aggregate income with high degrees of income inequality. 


\section{REFERENCES}

Atkinson, Anthony B., 1983, "How Progressive Should Income Tax Be?" in Social Justice and Public Policy (Cambridge: The MIT Press), pp. 295-314.

Cooter, Robert, and Elhanan Helpman, 1974, "Optimal Income Taxation for transfer Payments Under Different Social Welfare Criteria," Quarterly Journal of Economics, Vol. 88, pp. 656-70.

Dalton, Hugh, 1967, Principles of Public Finance, 4th edition (New York: Augustus M. Kelley Publishers).

Edgeworth, F. Y., 1925, "Formulae for Graduating Taxation," in Papers Relating to Political Economy, Vol. II (London: Macmillan), pp. 260-70.

Harberger, Arnold C., 1998, "Monetary and Fiscal Policy for Equitable Economic Growth," in Income Distribution and High-Quality Growth, ed. by Vito Tanzi and Ke-young Chu (Cambridge: The MTT Press), pp. 203-41.

Helpman, Elhanan, and Efraim Sadka, 1978, "The Optimal Income Tax," Journal of Public Economics, Vol. 9, pp. 383-93.

Lambert, Peter J., 1993, The Distribution and Redistribution of Income, 2nd edition (New York: Manchester University Press).

Messere, Ken C., 1993, Tax Policy in OECD Countries: Choices and Conflicts (Amsterdam: IBFD Publications BV).

Mirrlees, James A., 1971, "An Exploration in the Theory of Optimum Income Taxation," Review of Economic Studies, Vol. 38, pp. 175-208.

Musgrave, Richard A., and Tun Thin, 1948, "Income Tax Progression, 1929-48," Journal of Political Economy, Vol. 56, pp. 498-514.

Phelps, Edmund S., 1973, "The Taxation of Wage Income for Economic Justice," Quarterly Journal of Economics, Vol.87, pp. 331-54.

Seade, Jesus, 1977, "On the Shape of Optimal Tax Schedules," Journal of Public Economics, Vol. 7, pp.203-36.

Stern, Nicholas H., 1976, "On the Specification of Models of Optimum Income Taxation," Journal of Public Economics, Vol. 6, pp. 123-62. 
Tanzi, Vito, 1998, "Fundamental Determinants of Inequality and the Role of Government," WP/98/178, International Monetary Fund.

Tanzi, Vito, 1994, "The IMF and Tax Reform," in Tax Policy and Planning in Developing Countries, ed. by Amaresh Bagchi and Nicholas Stern (Delhi: Oxford University Press), pp. 445-73.

Tanzi, Vito, 1974, "Redistribution of Income through the Budget in Latin America," Banca Nazionale del Lavoro Quarterly Review, Vol. 27, pp. 65-87.

Tanzi, Vito, 1966, "Personal Income Taxation in Latin America: Obstacles and Possibilities," National Tax Journal, Vol. 19, pp. 156-62.

Tanzi, Vito, and Ke-young Chu (eds.), 1998, Income Distribution and High-Quality Growth (Cambridge: The MIT Press).

Tuomala, Matti, 1990, Optimal Income Tax and Redistribution (Oxford: Oxford University Press). 